\title{
Physicochemical parameters and consumer acceptance in espresso and american coffee pods
}

Parrado, L.X. ${ }^{\text {a*}}$; Bahamón, A.F. ${ }^{\text {a }}$; Gutierrez, N ${ }^{\text {a }}$.

a South colombian coffee research center-CESURCAFÉ. Universidad Surcolombiana, Neiva, Colombia.

*Corresponding author: u20142131808@usco.edu.co

\begin{abstract}
This study presents the consumer acceptance of coffee beverages made from espresso coffee pods (CCE) and american coffee pods (CCA), six quality attributes were evaluated by a sensory panel conformed to judges of different experience level. A physicochemical characterization was made for the coffee powder in CCA and CCE. The beverage preparation via different machines was made for to observe the influence on the consumers acceptance. The coffee powder in CCA showed high aw and high moisture content, this factors should affect the consumer perception; in general, a low acceptance level of coffee beverages made from CCE and CCA was observed, maybe because of the strong habit of consuming filtered coffees.
\end{abstract}

Keywords: Coffee; Espresso; American; sensory; physiochemical. 


\section{Introduction}

During the preparation of a coffee cup there is a solid-liquid extraction process in which the following steps occur: 1 . the water absorption of the ground coffee; 2 . the massive transfer of soluble from coffee grinds to hot water; and 3. the separation of the beverage extract and the spent coffee solids. [1]

Among the various processing techniques, filter coffee (drip filter) is the most used coffee obtained by the infusion method, while espresso coffee is the most appreciated coffee produced by the pressure method. In drip filtration methods, water at $92-96{ }^{\circ} \mathrm{C}$ flows through a bed of hardly compressed ground coffee and the extract drips vertically. The turbulence generated in the processing prevents the water from saturated [2]. The sensory properties of coffee prepared by dripping hot water through the ground grain on a filter are affected by particle size, solid / water ratio, contact time and temperature [3]. While an espresso coffee is obtained by the pressure method, water at approximately 9 bar and 88-92

${ }^{\circ} \mathrm{C}$ is forced to pass through the compacted coffee beans in a small preparation chamber [2], a fast preparation time and a fine particle size is necessary [4] since the result is strongly affected by the physical condition that controls the filtration process (grinding degree, temperature and water pressure and time) of percolation. The espresso is produced by professional machines and after specific operations carried out by expert hands that define the quality and quantity, the degree of grinding and compression of the coffee to obtain a cup of espresso with specific sensory properties. [5]

The Coffee pods, prepared in single-use (single-use) for coffee machines, have gained considerable popularity due to their end-use convenience and longer shelf life than conventional coffee [1]. The key point of this success is to allow any person, expert or nonexpert, to prepare it at any time and in all places (home, car, office and plane) where the limited quantities consumed do not justify or allow the use of professional machines [5]. The pods compatible with Keurig® are composed of a thermoformed multilayer highbarrier capsule, in which a paper or other filtering medium is attached to the side wall near the top of the capsule, forming a filter that separates the capsule into the pods. upper and lower compartments. The roasted and ground coffee beans are introduced into the upper compartment, and then sealed with an aluminum foil lid to form the final product of the PODS [1]. The preparation time in individual coffee is considerably shorter than conventional coffee (30-60 seconds versus 8-12 minutes), and as a result, the contact time with water is relatively shorter. In addition, since the preparation time, the water temperature, the pouring volume and the flow parameters are controlled by the microprocessor and controller of the coffee machine, and the coffee grinds are of portion size in the capsule, the intervention of the user is largely eliminated during the preparation process [1]. The pods compatible with Nespreso used by a simple technology that includes pre-packaged individual doses containing pre-measured and pre-stamped ground coffee. 
The ground coffee is hermetically sealed between two thin layers of filter paper, in aluminum or plastic pods [5]. Despite the considerable popularity, the information on the elaboration of coffee pods, the preparation of the drink and the acceptance by consumers is not available in the literature. The objective of this study is to investigate the influence of physicochemical parameters on the encapsulation and acceptance by coffee consumers.

\section{Materials and Methods}

Five commercial espresso coffee pods (CCE) and five commercial american coffee pods (CCA) were characterized in powder coffee and the beverages made from CCE in singledose machines C50-US-CW-NE coffee machine (Nespresso ${ }^{\circledR}$, Switzerland) and CCA extracted in the K50 CLASSIC SERIES coffee machine (Keurig®, United States) were characterized too. For CCE beverages the double-distilled water temperature was $70 \pm 2{ }^{\circ} \mathrm{C}$ and for CCA beverages it was $80 \pm 2{ }^{\circ} \mathrm{C}$. The extraction volume for espresso coffee was 40 $\mathrm{ml}$ (35 ml of prepared coffee and $5 \mathrm{ml}$ of foam) and for american coffee it was $177 \pm 2 \mathrm{ml}(6$ $\mathrm{oz}$ ). the extraction time for espresso coffee was $14 \pm 2$ seconds and for american coffee it was $25 \pm 2$ seconds. The water-coffee ratio was $20 \mathrm{~g} / 100 \mathrm{ml}$ for espresso and $7 \mathrm{~g} / 100 \mathrm{ml}$ for american coffee.

The physicochemical parameters evaluated in powder coffee and in the beverages included moisture content from wet basis (\%) in infrared balance OHAUS-MB45 (Parsippany, USA) (105 ${ }^{\circ} \mathrm{C}$ for $5 \mathrm{~min}$ ) according to Zanin et al. [6]; water activity using the AQUALAB VSA (Vapor Sorption Analyzer) equipment from Decagon Devices, Inc.; color (L) in powder coffee and color (L) of the beverages, using the digital colorimeter CR-410 (Konica Minolta Sensing Inc., Japan). Refractive indexes (expressed in ${ }^{\circ}$ Brix) were measured with the Atago PR-201 $\alpha$ digital refractometer, the titratable acidity (expressed as chlorogenic acid) was determined by titration and $\mathrm{pH}$ with the digital potentiometer BP- 3001 (Trans Instruments, Singapore). Measures was made in triplicate.

The sensory attributes of the beverages were evaluated using a QDA quantitative descriptive analysis, a sensory panel conformed to judges of different experience level: Colombian experts in tasting by SCAA methodology (p1), Colombian inexperienced coffee consumers (p2) and Colombian habitual specialty coffee consumers (p3) . The acceptance scale of 6 discrete values in which "I dislike extremely" was evaluated with 0 and "I like extremely" corresponded to 5 .

Anova tests were performed ( $\mathrm{p}<0.05$ ) to observe the statistically significant differences in the physicochemical parameters and on the quality attributes evaluated in the sensory panel for espresso coffee and american coffee. The statistical package StatGraphics Plus 5.1 for Windows (Manugistics, Inc., Rockville MD) was used. 


\section{Results and discussion}

\section{Physicochemical characterization}

Table 1 presents the results of the comparison of the powder coffee contained in CCE and CCA, in addition the comparison of the parameters obtained in the CCE and CCA beverages. The moisture content, aw, color, in powder coffee from CCE presented statistically significant differences $(\mathrm{P}<0.05)$ compared to CCA; likewise, in the analysis of the beverages, $\mathrm{pH}$, oBrix and color presented statistically significant differences $(\mathrm{P}<0.05)$ in the two types of drinks.

Table 1. Physicochemical parameters in powder coffee and beverages coffee extracted for espresso and american pods.

\begin{tabular}{clcc}
\hline \multicolumn{1}{c}{ Samples } & \multicolumn{1}{c}{ Parameters } & $\boldsymbol{C C E}$ & $\boldsymbol{C C A}$ \\
\hline \multirow{4}{*}{ Powder coffee } & Moisture content $(\%)$ & $2.71 \pm 0.62^{\mathrm{a}}$ & $4.51 \pm 1.52^{\mathrm{b}}$ \\
& Water activity (a $\left.\mathrm{a}_{\mathrm{w}}\right)$ & $0.25 \pm 0.11^{\mathrm{a}}$ & $0.38 \pm 0.11^{\mathrm{b}}$ \\
& Roasting degree (L) & $23.20 \pm 0.53^{\mathrm{a}}$ & $24.79 \pm 1.5^{\mathrm{b}}$ \\
& Titratable acidity & $1.68 \pm 0.4^{\mathrm{a}}$ & $1.85 \pm 0.36^{\mathrm{a}}$ \\
\hline \multirow{3}{*}{ Beverages } & $\mathrm{pH}$ & $5.21 \pm 0.13^{\mathrm{a}}$ & $4.92 \pm 0.11^{\mathrm{b}}$ \\
& Refractive index ( ${ }^{\circ}$ Brix) & $3.92 \pm 053^{\mathrm{a}}$ & $1.66 \pm 0.45^{\mathrm{b}}$ \\
& Color (L) & $32.04 \pm 2.89^{\mathrm{a}}$ & $29.80 \pm 1.15^{\mathrm{b}}$ \\
\hline
\end{tabular}

$(\mathrm{n}=3)$ mean \pm SD. Different letters, in the same row indicate significant difference $(\mathrm{P}<0.05)$.

The moisture content (\%) and aw in CCA is significantly higher than in CCE, this result may be influenced by the storage process that depends mainly on factors related to environmental coditions and technological factors such as the availability of oxygen and moisture, the exposed surface area, temperature and packing material [7] ; the CCE moisture content $(2.71 \pm 0.62 \%)$ is similar to that found by Lee et al. [8] for roasted and ground coffee. Apparently the result indicates that the CCE allow less water vapor exchange between the inside of the pods and the surrounding environment. Additionally, taking into account that Cardelly and Labuza [9] reported aw of $0.106 \%$ for roasted and ground coffee, the values of aw found for CCA $(0.38 \pm 0.11 \%)$ were much higher, unlike the values of aw for $\operatorname{CCE}(0.25 \pm 0.11 \%)$ that were closer to that found by the same author.

The color of roasting in the powder coffee of CCE and the CCA, showed significant differences $(\mathrm{p}<0.05)$, the magnitudes of the coordinate $\mathrm{L}$ obtained $(23.1 \pm 0.5$ and $24.1 \pm 1.7$ respectively) correspond to the degree of dark roasting according to the classification proposed by Franca et al. [10], this result is linked to the generalized concept for the preparation of espressos and American coffee; although L in CCA is significantly higher than in CCE, indicating less roasting degree and higher moisture content. 
The refractive index in the beverages, result higher in espresso than in american coffee as shown in Table 1, similar results were obtained by Gloess et al. [11] who determined that espresso coffee has a refractive index closer to $4.0 \%$, the author evaluated this parameters in different machines: a semi-automatic espresso machine, an automatic machine and a Nespresso brand single-use machine. In the american coffee, the same author determined refractive index slightly higher than $1.0 \%$; finding for the filtered coffee extract a refractive index of $1.03 \pm 0.01 \%$ and for the French press $1.43 \pm 0.01 \%$, these results are similar to those found for the CCA.

The $\mathrm{pH}$ in beverages is a characteristic that could suggest sensory acidity, according to the results shown in table 1 , the $\mathrm{pH}$ for the CCE is $5.2 \pm 0.1$ and for CCA of $4.9 \pm 0.1$, these results are similar to those found by Ludwig et al [2] who presented for the filtered coffee extract (water-coffee ratio of $6.0 \%$ and time extraction time of 75 seconds) a $\mathrm{pH}$ of $5.12 \pm 0.01$ and for espresso (15\% water-coffee ratio and 16 seconds of extraction) a $\mathrm{pH}$ of $4.9 \pm 0.01$. Other results such as those obtained by Fujioka et al. [12] showed that the $\mathrm{pH}$ in extracted coffee is related to the presence of chlorogenic acids; this author found that the $\mathrm{pH}$ in seven types of commercial coffees (with a water-coffee ratio of $3 \%$ and filtered) varies from $4.95 \pm 0.01$ to $5.99 \pm 0.01$ results very similar to those shown in table 1 .

\section{Sensorial analysis in espresso beverages and american coffee beverages.}

Table 2 shows the sensory acceptance of coffee beverages made from CCE and CCA, the crema (foam) was evaluated only in espresso coffee since american coffee does not generate it; statistically significative differences $(\mathrm{P}<0.05)$ between CCA and CCE was obtained only in Color (L), expressed by P2; while statistically significative differences by panelist type was obtained in all quality attributes, indicating higher strictness in the evalution expressed by P1 and P3, maybe because they have most experience and knowledge in coffee quality.

In the cream evaluation in CCE, the panelists criticized because this is disperse and not homogeneous. According to Gloess et al. [11] that compared several methods of preparation of espresso coffee, found that the crema of the espresso coffee pods was noticeably bigger and of a more intense color compared with other espressos coffees and that the espresso of the semiautomatic machine had the best foam. 
Table 2. Sensory Evaluation in beverages made from CCE and CCA

\begin{tabular}{lccc}
\hline \multirow{2}{*}{ Quality atributes } & \multirow{2}{*}{ Panelists } & \multicolumn{2}{c}{ Type } \\
\cline { 3 - 4 } Color & P1-P3 & $3.1 \pm 0.8^{\mathrm{a}}$ & $3.1 \pm 1.0^{\mathrm{a}}$ \\
& $\mathrm{P} 2$ & $3.8 \pm 0.9^{\mathrm{b}}$ & $3.6 \pm 0.8^{\mathrm{a}}$ \\
\hline \multirow{2}{*}{ Aroma } & P1-P3 & $2.2 \pm 1.2^{\mathrm{a}}$ & $1.6 \pm 0.9^{\mathrm{a}}$ \\
& $\mathrm{P} 2$ & $3.4 \pm 1.0^{\mathrm{b}}$ & $2.7 \pm 0.8^{\mathrm{b}}$ \\
\hline \multirow{2}{*}{ Flavor } & P1-P3 & $1.9 \pm 0.9^{\mathrm{a}}$ & $1.6 \pm 0.9^{\mathrm{a}}$ \\
& $\mathrm{P} 2$ & $3.0 \pm 1.3^{\mathrm{b}}$ & $3.0 \pm 1.2^{\mathrm{b}}$ \\
\hline \multirow{2}{*}{ Balance } & P1-P3 & $1.9 \pm 0.9^{\mathrm{a}}$ & $1.8 \pm 0.8^{\mathrm{a}}$ \\
& $\mathrm{P} 2$ & $3.2 \pm 1.3^{\mathrm{b}}$ & $2.6 \pm 1.2^{\mathrm{b}}$ \\
\hline \multirow{2}{*}{ Aftertaste } & P1-P3 & $1.7 \pm 1.1^{\mathrm{a}}$ & $1.2 \pm 1.2^{\mathrm{a}}$ \\
\hline \multirow{2}{*}{ Score global } & $\mathrm{P} 2$ & $3.1 \pm 1.8^{\mathrm{b}}$ & $2.9 \pm 1.1^{\mathrm{b}}$ \\
\hline \multirow{2}{*}{ crema } & P1-P3 & $1.8 \pm 0.9^{\mathrm{a}}$ & $1.4 \pm 0.9^{\mathrm{a}}$ \\
& $\mathrm{P} 2$ & $2.8 \pm 1.3^{\mathrm{b}}$ & $2.8 \pm 1.3^{\mathrm{b}}$ \\
\hline
\end{tabular}

$\mathrm{n}=3$ mean \pm SD. Different letters, in the same row for each treatment, indicate significant difference $(\mathrm{P} \leq 0.05)$. Different letters, in the colum for each quality attribute indicate significant difference $(\mathrm{P} \leq 0.05)$.

According to the observations expressed by panelists in the sensory questionnaire, they described greater sensory acidity in espresso coffee, while the results in table 1 , the highest titratable acidity and $\mathrm{pH}$ concentration occurs in american coffee, which would lead to thinking that it is possible to relate it to sensory acidity. To demonstrate this, it is necessary to do in-depth research of titratable acidity, $\mathrm{pH}$ and sensory acidity in an expert panel. The objective of this research was not to evaluate only expert tasters for this reason, we can not assure that the acidity in American coffee is directly due to the sensory acidity perceived by the panel.

\section{Conclusions}

A high moisture content and aw was found in powder coffee in commercial pods of CCA type, this can significantly affect sensory acceptance since high moisture contents can be indicators of product interaction with the environment given the high degree of hygroscopicity of the coffee. Likewise, the physicochemical parameters studied did not allow demonstrating the correlation between $\mathrm{pH}$ and acidity titratable versus sensory acidity, is recommended to deepen the subject by evaluating the acidity content through chemical analysis, titratable acidity, $\mathrm{pH}$ and sensory acidity. 
In all cases, it was found that the panelists evaluated separately the attributes of color and foam in relation to the other attributes associated with the senses of smell and taste.

In general, the american coffee and espresso coffee pods had low acceptance, perhaps due to the accentuated custom of consumption of filtered coffee in Colombia

\section{References}

[1] Wang, X., Willian, J., Fu, Y. y Lim, L.-T. (2016) "Effects of capsule parameters on coffee extraction in single-server brewer”, Food Research International, 89 (1), pp. 797-805.

[2] Ludwig, I.A., Sanchez L., Caemmerer, B., Kroh, L.W., de Peña, M.P. y Cid, C. (2012) "Extraction of coffee antioxidants: Impact of brewing time and method", Food Research International, 48 (1), pp. 57-64.

[3] Corrochano, B.R., Melrose, J.R., Bentley, A.C., Fryer, P.J. y Bakalis, S. (2014) “A new methodology to estimate the steady-state permeability of roast and ground coffee in packed beds", Journal of Food Engineering, 150, pp. 106-116.

[4] Lingle, T.R (1996) “The coffe brewing handbook”, Spelciality Coffe Association, Long Beach, California.

[5] Albanese, D., Di Mateo, M., Poiana, M. y Spagnamusso, S. (2009) "Espresso coffee (EC) by POD: Study of thermal profile during extraction process and influence of water temperature on chemical-physical and sensorial properties", Food Research International, 42 (5-6). Pp. 727-732.

[6] Zanin, R.C., Corso, M.P., Kitzberger, C.S.G., Scholz, M.B.D.S y Benassi, M.D.T (2016) "Good cup quality roasted coffes show wide variation in chlorogenic acids content”, LWT-Food Science and Technology, 74, pp. 480-483

[7] Manzocco, L. y Lagazio, C. (2009) "Coffee brew shelf life modelling by integration of acceptability and quality data”, Food Quality and Preference, 1 (20), pp. 24-29.

[8] Lee, S.J., Kim, M.K. y Lee, K.-G. (2017) "Effect of reversed coffee grinding and roasting process on physicochemical properties including volatile compound profiles", Innovative Food Science \& Emerging Technologies, 44, pp. 97-102.

[9] Cardelli, C. y Labuza, T.P. (2001) “Application of Weibull Hazard analysis to the determination of the shelf life of roasted and ground coffee", LWT-Food Science and Technology, 34 (5), pp. 273-278. 
[10] Franca, A.S., Oliveira, L.S., Oliveira, R.C.S., Agresti, P.C.M. y Augusti, R. (2009) “A preliminary evaluation of the effect of processing temperatura on coffee roasting degree assessment”, Journal of Food Engineering, 92 (3), pp. 345-352.

[11] Gloess, A.N., Schonbachler, B., Klopprogge, B., D’Ambrosio, L., Chatelain, K., Bongartz, A., Strittmatter, A., Rast, M. y Yeretzian, C. (2013) "Comparision of nine common coffee extraction methods: instrumental and sensory analysis", Eur Food Res Technol, 236 (4), pp. 607-627.

[12] Fujioka, K. y Shibamoto, T. (2008) "Chlorogenic acid and caffeine contents in various commercial brewed coffees”, Food Chemistry,106 (1), pp. 217-221. 